\title{
Catalytic cracking characteristics of bio-oil molecular distillation fraction
}

\author{
Zuogang Guo ${ }^{1,2}$, Shurong Wang ${ }^{1, *}$, Qianqian Yin $^{1}$, Guohui $\mathrm{Xu}^{1}$, \\ Zhongyang Luo ${ }^{1}$, Kefa Cen ${ }^{1}$, Torsten H. Fransson ${ }^{2}$ \\ ${ }^{1}$ State Key Laboratory of Clean Energy Utilization, Zhejiang University, Hangzhou, China \\ ${ }^{2}$ Department of Energy Technology, Royal Institute of Technology (KTH), Stockholm, Sweden \\ * Corresponding author. Tel: +86 571 87952801, Fax: +86 571 87951616, E-mail: srwang@zju.edu.cn
}

\begin{abstract}
The catalytic cracking characteristics of a bio-oil molecular distillation fraction using HZSM-5 were investigated. Properties of upgraded products and formation mechanism for gasoline components were discussed. The cracking products included $56.00 \mathrm{wt} . \%$ upgraded liquid oil, $1.27 \mathrm{wt} . \%$ coke and $42.73 \mathrm{wt} . \%$ gas products. The conversion yield for components in bio-oil fraction was influenced by their cracking reactivity and their concentration. The cracking reactivity of phenols was strongly affected by the connected functional groups. Alkyl groups had a positive influence on phenols reactivity, while methoxy groups had a negative influence. Reactivity of typical phenols in bio-oil fraction followed the order: Phenol, 4-methyl-> Phenol, 4-ethyl-2methoxy->Phenol $>$ Phenol, 2-methoxy-. Expected gasoline components including ethylbenzene, $p$-xylene and benzene, 1-ethyl-3-methyl were detected in the upgraded liquid oil, which indicates liquid hydrocarbon fuels can be produced from bio-oil. A two-step reaction mechanism was proposed which successfully explains the formation routes for gasoline components. In the first step, dehydration and decarbonylation reactions generate $\mathrm{H}_{2} \mathrm{O}, \mathrm{CO}$ and $\mathrm{CO}_{2}$. The cracking reaction produces free radicals including $-\mathrm{CH}_{3},-\mathrm{CH}_{2}-$ and $-\mathrm{H}$. In the second step, these free radicals form gaseous and liquid hydrocarbons.
\end{abstract}

Keywords: Bio-oil, Molecular Distillation Technology, Cracking, HZSM-5, Gasoline Components

\section{Introduction}

Supply security and price concerns for fossil oil have led to renewed interests in renewable energy resources as alternative feedstocks for the production of transport fuels. Biomass resources are among the most promising feedstocks because of their abundant reserves and carbon-neutral property. Fast pyrolysis technology is a key thermochemical process that can convert solid biomass waste into liquid bio-oil under atmospheric pressure[1-3]. Bio-oil has better fuel properties in terms of transportation suitability and energy density than solid biomass waste. However, it is only used as fuel in boiler[4, 5] but can not be directly substituted for fossil fuels because of its high viscosity and corrosiveness[6, 7]. Bio-oil refinement has become a key issue for its utilization as a high-grade transport fuel.

Catalytic esterification has been used to decrease corrosiveness of bio-oil by converting carboxylic acids into neutral esters. Carboxylic acid conversion of approximately $90 \%$ was achieved and the corrosiveness of bio-oil obviously decreased[8, 9]. Emulsification can be used to refine bio-oil by mixing diesel and bio-oil to produce a homogeneous fuel. Zhang et al. [10] studied the emulsification behavior of diesel and bio-oil using nonionic surfactants. The effects of HLB value, emulsifying temperature and time on emulsion stability were investigated. Wang et al. [11] compared the emulsification properties of different bio-oils and diesel combined at the same ratio(diesel/emulsifier/bio-oil was $92 \mathrm{wt} . \% / 3 \mathrm{wt} \% / 5 \mathrm{wt} . \%$ ). Emulsion made from diesel and straw bio-oil showed the best stability. The corrosion properties of emulsions on four metals were measured at different temperatures by $\mathrm{Lu}[12]$. Ikura et al. [13] determined the relationship between process conditions, emulsion stability and processing costs using bio-oil and No.2 diesel. Catalytic esterification and emulsification can improve bio-oil fuel properties to a certain extent, but they can not convert oxygenated bio-oil into pure liquid hydrocarbon fuels. 
Among the technologies available for bio-oil upgrading, catalytic hydrogenation and catalytic cracking have been used to produce hydrocarbon fuels from oxygenated bio-oil. Oxygen in bio-oil was removed in the form of $\mathrm{CO}_{2}$ and $\mathrm{H}_{2} \mathrm{O}$ during catalytic hydrogenation[14, 15]. Hydrogenation process can only occur under high temperature and high hydrogen pressure, which limit its economic efficiency. By contrast, catalytic cracking technology is more economically efficient. It can produce liquid hydrocarbon fuels from bio-oil without consuming hydrogen. Adjaye et al. [16] investigated upgrading research of a fast pyrolysis bio-oil using different catalysts. Aromatic and aliphatic hydrocarbons were obtained. Gayubo et al. [17] produced olefins by catalytic transformation of crude bio-oil using HZSM-5. Besides, other researchers studied the cracking behavior of bio-oil using its model components[18, 19]. The key problem in catalytic cracking is the high coke yield, which leads to catalyst deactivation. Catalytic cracking research has mainly focused on crude bio-oil in recent years. The complex composition of crude bio-oil means that qualitative and quantitative analysis of its components is difficult. What more, the strong interaction between different components enhances the probability of coke formation. In the present study, the cracking behavior on HZSM-5 zeolite was investigated for a unique bio-oil fraction produced by molecular distillation technology.

\section{Methodology}

\subsection{Experimental methods}

HZSM-5(Si/Al=25) was used as the catalyst for cracking of a Bio-oil Middle Fraction (BMF), which was obtained by molecular distillation using KDL5 equipment as described in our earlier papers[20, 21]. Cracking experiment was performed upon a fixed-bed reactor at $330^{\circ} \mathrm{C}$. The liquid hourly space velocity (LHSV) was $2 \mathrm{~h}^{-1}$ with a HZSM-5 volume of $2 \mathrm{ml}$. $\mathrm{BMF}$ was first vaporized in the pre-heater and then carried to the catalytic bed by a stream of nitrogen. After each run, catalytic bed was subjected to stripping with nitrogen for 40 minutes, with the aim of eliminating the reaction medium components that may remain adsorbed on the catalyst.

\subsection{Catalyst characterization}

Textural properties were determined by $\mathrm{N}_{2}$ adsorption-desorption isotherms measured at $196^{\circ} \mathrm{C}$ below zero on a Quantachrom-Autosorb-1-C apparatus. HZSM-5 had a BET surface area of $283.97 \mathrm{~m}^{2} / \mathrm{g}$, a pore volume of $0.07 \mathrm{~cm}^{3} / \mathrm{g}$ and an average pore size of $5.65 \mathrm{~nm}$. Coke deposition on the catalyst was measured during temperature-programmed combustion on a Mettler-Toledo TGA/SDTA851e thermogravimetric balance. Sample of approximately $15 \mathrm{mg}$ was burnt at $30-650^{\circ} \mathrm{C}$ with an oxygen flow rate of $60 \mathrm{ml} / \mathrm{min}$. The total coke weight was calculated according to the coke content and the total catalyst weight.

\subsection{Analysis of liquid products}

Liquid products were identified on a Trace DSQII system using a $30 \mathrm{~m} \times 0.25 \mathrm{~mm} \times 0.25 \mu \mathrm{m}$ Agilent DB-WAX capillary column. The oven was heated at $40^{\circ} \mathrm{C}$ for $1 \mathrm{~min}$ and then the temperature was increased to $240^{\circ} \mathrm{C}$ at $8{ }^{\circ} \mathrm{C} / \mathrm{min}$ and held at this temperature. Data were acquired using Xcalibur software according to the NIST mass spectra library data base. 


\section{Results and discussion}

\subsection{Distribution of cracking products}

Upgraded Liquid Oil (ULO), coke and gas products were obtained from catalytic cracking of BMF. ULO yield ( $\left.\mathrm{Y}_{\mathrm{ULO}}\right)$ and coke yield ( $\left.\mathrm{Y}_{\text {coke }}\right)$ were calculated from Eq. (1) and (2). Yield of gas products $\left(\mathrm{Y}_{\text {gas }}\right)$ was calculated by difference.

$$
\begin{aligned}
& \mathrm{Y}_{\mathrm{ULO}}=100 \mathrm{wt} \% \times \text { Weight }_{\mathrm{ULO}} \div \text { Weight }_{\text {BMF }} \\
& \mathrm{Y}_{\text {Coke }}=100 \mathrm{wt} \% \times \text { Weight }_{\text {Coke }} \div \text { Weight }_{\mathrm{BMF}}
\end{aligned}
$$

Values for $\mathrm{Y}_{\mathrm{ULO}}, \mathrm{Y}_{\text {coke }}$ and $\mathrm{Y}_{\text {gas }}$ were 56.00 wt.\%, 1.27 wt.\% and 42.73 wt.\%, respectively. Gas products accounted for large proportion. The coke yield was low, which means that cracking of bio-oil fractions is a feasible method for decreasing catalyst coking. Graca et al. [22] obtained a coke yield of $16 \mathrm{wt} . \%$ for cracking of a mixture of bio-oil and gasoil over ZSM-5. Adjaye et al. [23] obtained a coke yield about $22.5 \mathrm{wt} . \%$ for cracking of maple pyrolysis oil over HZSM-5 and silica-alumina catalysts. Thus, cracking of bio-oil fractions has obvious superiority over crude bio-oil in decreasing the coke yield.

\subsection{Analysis of liquid products}

Compounds in BMF and ULO were identified by GC-MS and quantified using peak area normalization method. The conversion yield was determined as a measure of reactivity during cracking, which was calculated by Eq. (3).

$$
\eta_{\mathrm{i}}=100 \% \times\left(\mathrm{C}_{1 \mathrm{i}}-\mathrm{Y}_{\mathrm{ULO}} \times \mathrm{C}_{2 \mathrm{i}}\right) \div \mathrm{C}_{1 \mathrm{i}}
$$

Where $\eta_{i}$ represents the conversion yield of compound $i . \mathrm{C}_{1 i}$ is its content in $\mathrm{BMF}$ and $\mathrm{C}_{2 i}$ is its content in ULO. $\mathrm{Y}_{U L O}$ is the yield of ULO with a value of $56.00 \mathrm{wt} \% \%$ in this experiment.

\subsubsection{Cracking behavior of different compounds}

Reactivity of different compounds is indicated by conversion yields. Typical compounds in BMF are listed from Table 1 to Table 3. The conversion yield of a compound during the cracking is determined by two main factors. The first is its cracking reactivity. Compounds with higher reactivity may have a higher conversion yield. The second is its concentration in BMF. Compounds with higher concentration may have a lower conversion yield because of catalyst deactivation. In Table 1, compounds with content below $1 \%$ had conversion yield of $100 \%$. For example, 4-methyl-5H-furan-2-one and 2-furanmethanol were absolutely cracked. Three compounds had high content but were completely cracked. It indicated that they were very active during the cracking process. Combining with their concentration in BMF and conversion yields, the reactivity of these three compounds followed the order: Furan, 2,5diethoxytetrahydro- > 2-Cyclopenten-1-one, 3-methyl- > 2-Cyclopenten-1-one, 2-hydroxy-. 
Table 1 Compounds in BMF with the highest conversion yields

\begin{tabular}{cccc}
\hline Compounds & \multicolumn{2}{c}{ Content $\mathbf{( \% )}$} & \multirow{2}{*}{$\eta_{i}(\%)$} \\
\cline { 2 - 3 } & $\mathrm{C}_{1}$ & $\mathrm{C}_{2}$ & \\
\hline Heptane, 1,1-diethoxy- & 3.41 & 0.44 & 92.77 \\
Eugenol & 1.24 & 0.07 & 96.84 \\
4-Methyl-5H-furan-2-one & 0.36 & 0.00 & 100.00 \\
2-Furanmethanol & 0.50 & 0.00 & 100.00 \\
1,2-Ethanediol, monoacetate & 0.72 & 0.00 & 100.00 \\
2-Cyclopenten-1-one, 2-hydroxy- & 1.28 & 0.00 & 100.00 \\
2-Cyclopenten-1-one, 3-methyl- & 1.52 & 0.00 & 100.00 \\
Furan, 2,5-diethoxytetrahydro- & 13.11 & 0.00 & 100.00 \\
\hline
\end{tabular}

The conversion yields for compounds listed in Table $2 \mathrm{v}$ aried from $60 \%$ to $90 \%$. Phenol derivates were the predominant chemicals in Table 2 and showed a clear cracking principle. Cracking activity of phenols was strongly affected by connected functional groups. Methoxy groups had a negative influence while alkyl groups had a positive influence on the phenols reactivity. Phenol had a conversion yield of $75.63 \%$. This decreased to $59.87 \%$ when a methoxy group was attached, such as Phenol, 2-methoxy-. The conversion yield increased to $89.20 \%$ when a methyl group was attached, such as Phenol, 4-methyl-. When phenol derivates had alkyl and methoxy groups at the same time, their conversion yields were intermediate between phenol and Phenol, 4-methyl-. The cracking activity of different phenol derivates followed an order as: Phenol, 4-methyl- $>$ Phenol, 4-ethyl-2-methoxy- $>$ Phenol $>$ Phenol, 2methoxy-.

Table 2 Compounds in BMF with moderate conversion yields

\begin{tabular}{cccc}
\hline Compounds & \multicolumn{2}{c}{ Content $(\%)$} & \multirow{2}{*}{$\eta_{i}(\%)$} \\
\cline { 2 - 3 } & $\mathrm{C}_{1}$ & $\mathrm{C}_{2}$ & \\
\hline Phenol, 2-methoxy- & 5.04 & 3.61 & 59.87 \\
Ethanol, 2,2-diethoxy- & 16.43 & 8.18 & 72.10 \\
Phenol & 1.45 & 0.63 & 75.63 \\
Phenol, 2-methoxy-4-methyl- & 4.98 & 2.02 & 77.29 \\
2(5H)-Furanone & 1.13 & 0.42 & 79.16 \\
Phenol, 4-ethyl-2-methoxy- & 1.14 & 0.36 & 82.31 \\
2-Cyclopenten-1-one, 2-hydroxy-3-methyl- & 2.56 & 0.57 & 87.55 \\
Phenol, 2-methyl- & 1.87 & 0.40 & 88.02 \\
Phenol, 4-methyl- & 1.61 & 0.31 & 89.20 \\
2-Pentanone, 5,5-diethoxy- & 3.02 & 0.54 & 89.99 \\
\hline
\end{tabular}

Compounds in Table 3 had lower conversion yields than those in Table 1 and Table 2. Acetic acid, 2-Propanone, 1-hydroxy- and furfural were the most abundant compounds in Table 3. Subsequent to the cracking process, their contents in ULO increased. Content of acetic acid increased from $15.70 \%$ to $28.00 \%$. This phenomenon can be well explained as follows. Compounds with high activity were cracked firstly, which generated gaseous hydrocarbons and micro-coke. The active surface of HZSM-5 catalyst was clogged by the micro-coke and deactivated. The cracking of the less reactive compounds, like acetic acid, was interrupted. Thus, the relative concentration of less reactive compounds in the upgraded liquid oil increased. The conversion yields of these compounds can be calculated by Eq. (3). The conversion yield of acetic acid was as low as $0.1 \%$, followed by furfural (15.24\%) and 2Propanone, 1-hydroxy (26.85\%). 
Table 3 Compounds in BMF with the lowest conversion yields

\begin{tabular}{cccc}
\hline Compounds & \multicolumn{2}{c}{ Content (\%) } & \multirow{2}{*}{$\eta_{i}(\%)$} \\
\cline { 2 - 3 } & $\mathrm{C}_{1}$ & $\mathrm{C}_{2}$ & \\
\hline Acetic acid & 15.70 & 28.00 & 0.10 \\
2-Cyclopenten-1-one & 1.01 & 1.66 & 8.37 \\
Furfural & 3.11 & 4.71 & 15.24 \\
2-Propanone, 1-hydroxy- & 9.50 & 12.40 & 26.85 \\
Butanoic acid, 2-methyl- & 1.13 & 1.23 & 38.96 \\
1-Hydroxy-2-butanone & 0.97 & 1.03 & 40.47 \\
2(5H)-Furanone, 5-methyl- & 0.92 & 0.68 & 58.76 \\
\hline
\end{tabular}

\subsubsection{Identification of the gasoline components}

Bio-oil is considered as one of the most promising substitute for fossil fuels. The most important issue involves the removal of bio-oil oxygen and its conversion to pure liquid hydrocarbons. Some liquid hydrocarbons and other new products were detected in ULO by GC-MS technology. Liquid hydrocarbons were listed in Table 4. The new products in ULO accounted for a total content of $29.74 \%$, including liquid hydrocarbons, liquid ethers and esters. Besides liquid hydrocarbons, ethers and esters can be used as transport fuels or to produce emulsification fuels with gasoline and diesel. Aromatic hydrocarbons, such as toluene, ethylbenzene and benzene, 1-ethyl-3-methyl-, were produced during this cracking experiment. Elucidation the mechanism for formation of these aromatic hydrocarbons is very important for hydrocarbon fuels production from oxygenated bio-oil.

Table 4 Gasoline compounds in the ULO

\begin{tabular}{cccc}
\hline Compounds & Content (\%) & Compounds & Content (\%) \\
\hline Toluene & 0.31 & Benzene, 1,3-diethyl- & 0.49 \\
Ethylbenzene & 0.55 & Benzene, 1,2,3-trimethyl- & 0.44 \\
p-Xylene & 1.69 & Naphthalene, 1,4,6-trimethyl- & 0.42 \\
Benzene, 1-ethyl-3-methyl- & 2.76 & Naphthalene, 1,7-dimethyl- & 0.50 \\
\hline
\end{tabular}

\subsection{Mechanism of aromatic hydrocarbons production}

Transport fuel is the ultimate aim of bio-oil refinement. Liquid hydrocarbons were detected after cracking of BMF. Exploring the formation mechanism of liquid hydrocarbons was very important for selective enhancement of expected products. In earlier literatures[18, 19], researchers suggested reaction pathways for chemical groups such as acids, phenols and alcohols. But the exact formation mechanism of the liquid hydrocarbons was not proposed. Here, we proposed a two-step mechanism model to explain how the liquid hydrocarbons were produced from oxygenated bio-oil.

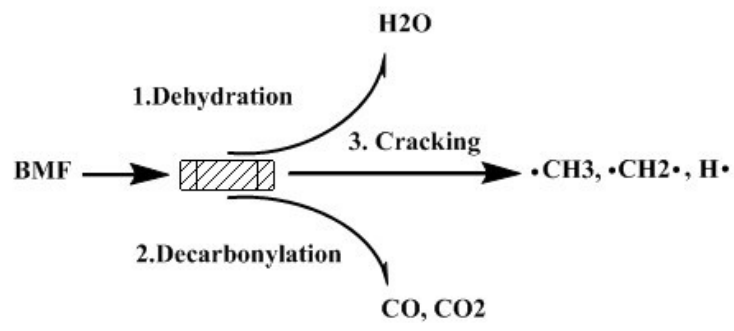

Fig. 1 The first step of the cracking mechanism 
The first step is shown in Fig. 1 and it consists of three main reactions, dehydration, decarbonylation and a cracking reaction. Dehydration reaction produces a $\mathrm{H}_{2} \mathrm{O}$ molecule, while decarbonylation reaction generates $\mathrm{CO}$ and $\mathrm{CO}_{2}$ molecules. The cracking reaction results in free radicals including $-\mathrm{CH}_{3},-\mathrm{CH}_{2}$ - and $-\mathrm{H}$. All these free radicals participate in the second step to form liquid hydrocarbons.

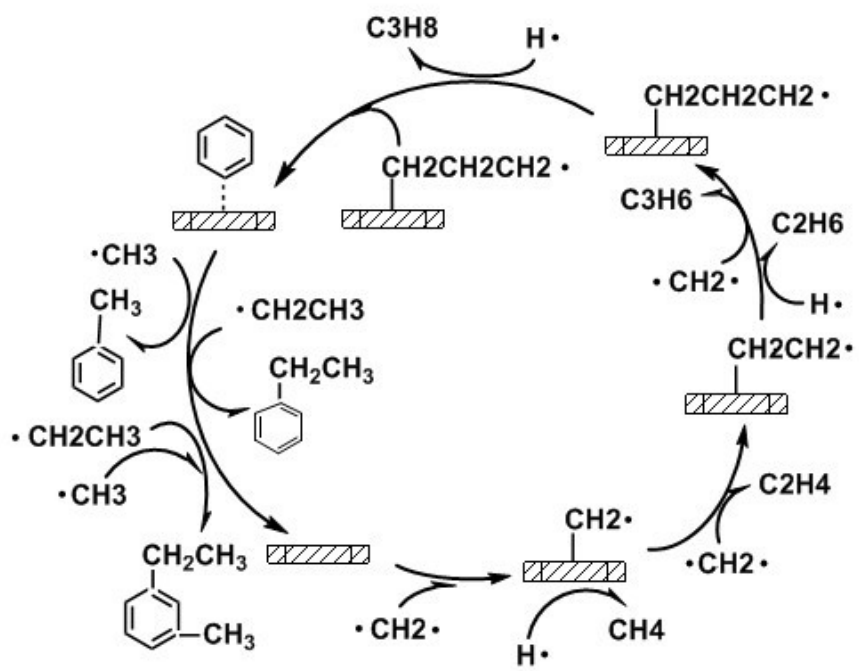

Fig. 2 The second step of the cracking mechanism

Fig. 2 gives a clear overview of the formation process for gaseous hydrocarbons $\left(\mathrm{CH}_{4}, \mathrm{C}_{2} \mathrm{H}_{4}\right.$, $\mathrm{C}_{2} \mathrm{H}_{6}, \mathrm{C}_{3} \mathrm{H}_{6}$ and $\mathrm{C}_{3} \mathrm{H}_{8}$ ) and liquid hydrocarbons (toluene, ethylbenzene and benzene, 1-ethyl3-methyl- ). The reaction starts with adsorption of $-\mathrm{CH}_{2}$ - on HZSM-5 catalyst surface. When another $-\mathrm{CH}_{2}$ - group is adsorbed to the catalyst surface, the carbon chain becomes longer to form $-\mathrm{CH}_{2} \mathrm{CH}_{2}$ - group. Some of the $-\mathrm{CH}_{2} \mathrm{CH}_{2}$ - groups desorb to form ethylene $\left(\mathrm{C}_{2} \mathrm{H}_{4}\right)$. Some of the $-\mathrm{CH}_{2} \mathrm{CH}_{2}$ - groups further adsorb on the catalyst surface to continue the cycle. Ethane $\left(\mathrm{C}_{2} \mathrm{H}_{6}\right)$ is released when the adsorbed $-\mathrm{CH}_{2} \mathrm{CH}_{2}$ - groups are attacked by $-\mathrm{H}$ groups. The carbon chain increases to form $-\mathrm{CH}_{2} \mathrm{CH}_{2} \mathrm{CH}_{2}$ - when an adsorbed $-\mathrm{CH}_{2} \mathrm{CH}_{2}$ - group is attacked by another $-\mathrm{CH}_{2}$ - group. Propylene $\left(\mathrm{C}_{3} \mathrm{H}_{6}\right)$ and propane $\left(\mathrm{C}_{3} \mathrm{H}_{8}\right)$ are formed via the same mechanism as for ethylene and ethane. Adsorbed $-\mathrm{CH}_{2} \mathrm{CH}_{2}-\mathrm{CH}_{2}-$ groups undergo an aromatization reaction to produce active benzene, which is further attacked by $-\mathrm{CH}_{3}$ and $\mathrm{CH}_{2} \mathrm{CH}_{3}$ groups to form liquid aromatic hydrocarbons. Another cycle is started by $-\mathrm{CH}_{2}-$ group attacking the blank HZSM-5 catalyst surface.

\section{Conclusion}

A bio-oil fraction separated by molecular distillation technology was subjected to catalytic cracking for gasoline production using HZSM-5 catalyst. Gasoline components were detected in the upgraded liquid oil. A two-step mechanism model for gasoline components production was proposed.

The coke yield for cracking of the bio-oil fraction was only $1.27 \mathrm{wt} . \%$, which was much lower than that for crude bio-oil. Compounds in bio-oil fraction were classified into three groups according to their conversion yields. Furan, 2,5-diethoxytetrahydro- was one of the most abundant components in bio-oil fraction, but was completely cracked. Reactivity of phenol derivatives was strongly affected by the connected functional groups. Methoxy groups had a negative influence on their cracking reactivity, while alkyl groups had a positive influence. The cracking activity of typical phenol derivates in bio-oil middle fraction followed an order 
as: phenol, 4-methyl-> phenol, 4-ethyl-2-methoxy->phenol> phenol, 2-methoxy-. Acetic acid and 2-propanone, 1-hydroxy- showed much lower cracking reactivity.

A two-step mechanism model was proposed according to the gasoline components detected in the upgraded liquid oil. Oxygenated compounds in bio-oil were subjected to dehydration, decarbonylation and cracking reactions in the first step. Free radicals including $-\mathrm{CH}_{3},-\mathrm{CH}_{2}$, and $-\mathrm{H}$ were involved in the second step to form gaseous hydrocarbons and liquid gasoline components (toluene, ethylbenzene and benzene, 1-ethyl-3-methyl- and etc.).

\section{Acknowledgement}

The authors appreciate financial support granted from the International Science and Technology Cooperation Program (2009DFA61050), the National High Technology Research and Development Program (2009AA05Z407), the National Natural Science Foundation (90610035), the Program of Introducing Talents of Discipline to University (B08026) and the National Basic Research Program of China (2007CB210204).

\section{References}

[1] Q. Wang, Z.Y. Luo, S.R. Wang, K.F. Cen, Products of high-grade liquid fuels by biomass fast pyrolysis, Journal of Zhejiang University(Engineering Science), 2010, pp. 988-990.

[2] Q. Lu, X.F. Zhu, Q.X. Li, Q.X. Guo, Q.S. Zhu, Biomass Fast Pyrolysis for Liquid Fuels, Progress in Chemistry, 2007, pp. 1064-1071.

[3] A.V. Bridgwater, G.V.C. Peacocke, Fast pyrolysis processes for biomass, Renewable \& Sustainable Energy Reviews, 2000, pp. 1-73.

[4] D. Chiaramonti, A. Oasmaa, Y. Solantausta, Power generation using fast pyrolysis liquids from biomass, Renewable \& Sustainable Energy Reviews, 2007, pp. 1056-1086.

[5] S. Czernik, A.V. Bridgwater, Overview of applications of biomass fast pyrolysis oil, Energy \& Fuels, 2004, pp. 590-598.

[6] N. Ozbay, A.E. Putun, B.B. Uzun, E. Putun, Biocrude from biomass: pyrolysis of cottonseed cake, Renewable Energy, 2001, pp. 615-625.

[7] M. Garcia-Perez, A. Chaala, H. Pakdel, D. Kretschmer, D. Rodrigue, C. Roy, Evaluation of the influence of stainless steel and copper on the aging process of bio-oil, Energy \& Fuels, 2006, pp. 786-795.

[8] Y.L. Gu, Z.G. Guo, L.J. Zhu, G.H. Xu, S.R. Wang, Experimental research on catalytic esterification of bio-oil volatile fraction, 2010 Asia-Pacific Power and Energy Engineering Conference, 2010, DOI: 10.1109/APPEEC.2010.5448436.

[9] Y. Tang, W.J. Yu, L.Y. Mo, H. Lou, X.M. Zheng, One-step hydrogenation-esterification of aldehyde and acid to ester over bifunctional Pt catalysts: A model reaction as novel route for catalytic upgrading of fast pyrolysis bio-oil, Energy \& Fuels, 2008, pp. 3484-3488.

[10] Z. Jian, L. Wenzhi, L. Qiang, Z. Xifeng, Emulsification Technology of Bio-oil in Diesel with Combined Surfactants, Transactions of the Chinese Society of Agricultural Machinery, 2009, pp. 102-106.

[11] W. Qi, L. Xinbao, W. Shurong, L. Zhongyang, C. Kefa, Experimtnal research on emulsions from biomass pyrolysis liquid and diesel, Acta Energiae Solaris Sinica, 2010, pp. 380-384. 
[12] Q. Lu, J. Zhang, X.F. Zhu, Corrosion properties of bio-oil and its emulsions with diesel, Chinese Science Bulletin, 2008, pp. 3726-3734.

[13] M. Ikura, M. Stanciulescu, E. Hogan, Emulsification of pyrolysis derived bio-oil in diesel fuel, Biomass \& Bioenergy, 2003, pp. 221-232.

[14] D.C. Elliott, Historical developments in hydroprocessing bio-oils, Energy \& Fuels, 21 2007, pp. 1792-1815.

[15] J. Wildschut, J. Arentz, C.B. Rasrendra, R.H. Venderbosch, H.J. Heeres, Catalytic Hydrotreatment of Fast Pyrolysis Oil: Model Studies on R eaction Pathways for the Carbohydrate Fraction, Environmental Progress \& Sustainable Energy, 2009, pp. 450-460.

[16] J.D. Adjaye, N.N. Bakhshi, Production of hydrocarbons by catalytic upgrading of a fast pyrolysis bio-oil: 1. conversion over various catalysts, Fuel Processing Technology, 1995, pp. 161-183.

[17] A.G. Gayubo, B. Valle, A.T. Aguayo, M. Olazar, J. Bilbao, Olefin Production by Catalytic Transformation of Crude Bio-Oil in a Two-Step Process, Industrial \& Engineering Chemistry Research, 2010, pp. 123-131.

[18] A.G. Gayubo, A.T. Aguayo, A. Atutxa, R. Aguado, J. Bilbao, Transformation of oxygenate components of biomass pyrolysis oil on a HZSM-5 zeolite. I. Alcohols and phenols, Industrial \& Engineering Chemistry Research, 2004, pp. 2610-2618.

[19] J.D. Adjaye, N.N. Bakhshi, Catalytic conversion of a biomass-derived oil to fuels and chemicals.1. model-compound studies and reaction pathways, Biomass \& Bioenergy, 1995, pp. 131-149.

[20] S.R. Wang, Y.L. Gu, Q. Liu, Y. Yao, Z.G. Guo, Z.Y. Luo, K.F. Cen, Separation of biooil by molecular distillation, Fuel Processing Technology, 2009, pp. 738-745.

[21] Z.G. Guo, S.R. Wang, Y.L. Gu, G.H. Xu, X. Li, Z.Y. Luo, Separation characteristics of biomass pyrolysis oil in molecular distillation, Separation and Purification Technology, 2010, pp. 52-57.

[22] I. Graca, F.R. Ribeiro, H.S. Cerqueira, Y.L. Lam, M.B.B. de Almeida, Catalytic cracking of mixtures of model bio-oil compounds and gasoil, Appl. Catal. B-Environ., 2009, pp. 556563.

[23] J.D. Adjaye, S.P.R. Katikaneni, N.N. Bakhshi, Catalytic conversion of a biofuel to hydrocarbons: Effect of mixtures of HZSM-5 and silica-alumina catalysts on pr oduct distribution, Fuel Processing Technology, 1996, pp. 115-143. 